\title{
Lusioersily
}

\section{Nursing Home Manager's Knowledge, Attitudes and Beliefs about Advance Care Planning for people with Dementia in Long-term Care Settings : A Cross-Sectional Survey}

Beck, ER., Mcllfatrick, S., Hasson, F., \& Leavey, G. (2017). Nursing Home Manager's Knowledge, Attitudes and Beliefs about Advance Care Planning for people with Dementia in Long-term Care Settings : A Cross-Sectional Survey. Journal of Clinical Nursing, n/a(n/a). https://doi.org/10.1111/jocn.13690

Link to publication record in Ulster University Research Portal

Published in:

Journal of Clinical Nursing

Publication Status:

Published online: 09/02/2017

DOI:

10.1111/jocn.13690

Document Version

Author Accepted version

\section{General rights}

Copyright for the publications made accessible via Ulster University's Research Portal is retained by the author(s) and / or other copyright owners and it is a condition of accessing these publications that users recognise and abide by the legal requirements associated with these rights.

\section{Take down policy}

The Research Portal is Ulster University's institutional repository that provides access to Ulster's research outputs. Every effort has been made to ensure that content in the Research Portal does not infringe any person's rights, or applicable UK laws. If you discover content in the Research Portal that you believe breaches copyright or violates any law, please contact pure-support@ulster.ac.uk. 


\section{Nursing Home Manager's Knowledge, Attitudes and Beliefs about Advance Care Planning for people with Dementia in Long-term Care Settings : A Cross- Sectional Survey}

\section{Abstract}

Aim: To examine nursing home managers' knowledge, attitudes, beliefs and current practice regarding advanced care planning for people with dementia in long term care settings informed by the Theory of Planned Behaviour.

Background: Internationally advance care planning is advocated for people with dementia. However, evidence suggests that discussions with people with dementia are rare, particularly in long-term care settings. Whilst nursing home managers can be considered central to implementation in this setting, there is a dearth of research that has examined their perspective. This study reports on their role with regards to advance care planning, and the perceived factors which influence this.

Design: A cross-sectional postal survey was carried out as part of a larger scale sequential explanatory mixed methods study between January-March 2015.

Setting and Participants: Nursing home managers in a region in the UK $(n=178)$.

Results: A response rate of $66 \%(n=116)$ was achieved. Nursing home managers demonstrated a lack of knowledge of advance care planning; with negative attitudes underpinned by concerns regarding the capacity and lack of perceived benefits to the person with dementia. Currently they do not view ACP as part of their role, with lack of ownership impacting upon current practice behaviours.

Conclusions: Whilst nursing home managers recognise the potential benefits of advance care planning, barriers and challenges create a reluctance to facilitate. Targeted training to address the knowledge deficit is required, with the wider components of advance care 
planning promoted. There is a need for greater role clarification to ensure nurses in longterm care settings identify with the process in the future. A gap between rhetoric and reality of implementation is evident, therefore long-term care settings must critically examine system, organisational and individual factors for failure to implement advance care planning for people with dementia.

Word count: 5472

Key Words: Advance care planning; cognitive impairment; Dementia; Long-term care settings: Nursing Homes; Nurses; Knowledge; Attitudes; Practice 
What does this paper contribute to the wider global clinical community?

- Nursing home managers have a clear role to play in the facilitation of advance care planning in the long-term care setting which is currently unrealised due to a lack of role clarification.

- Negative connotations and attitudes towards ACP for people with dementia has impeded opportunities for people with dementia to engage in this setting.

- There is a need for targeted and improved advance care planning training to address the knowledge deficit evidenced by this study, which promote the wider aspects of ACP. 


\section{Introduction}

Globally health care cultures have increasingly recognised the rights of individuals to be involved in decisions relating to their health (WHO 2011). This has resulted in numerous international countries enshrining the concept of personal autonomy into their legal and healthcare systems (Patient Self-Determination Act 1991 [US], Mental Capacity Act 2005 [UK], Medical Treatment (Health Directions) Act 2006 [Australia], Assisted Decision-Making (Capacity) Bill 2013 [Ireland]). As a consequence, the process of advance care planning (ACP) has been advocated across various clinical settings, including long-term care settings, becoming the cornerstone of end of life care policies globally (Dening et al. 2011). Robinson et al. (2012) in their systematic review, defined ACP as "a multi-stage process whereby a patient and their carers achieve a shared understanding of their goals and preferences for future care" (Robinson et al. 2012, p263). International policy advocates that health professionals need to ensure that everyone is given the opportunity to engage in ACP (United Nations Convention on the Rights of People with Disabilities 2009, WHO 2011). However, research indicates that nurses across various clinical settings are uncertain with regards to implementation of ACP. (Rurup et al. 2006, Gott et al. 2009, Robinson et al. 2013).

The potential of ACP to improve the overall quality of care provided to people with dementia, particularly as they enter the last phase of their life has been outlined in the literature (Hertogh 2006, Brinkman-Stoppalenburg et al. 2014). It can be argued that the value and recognition of the role of ACP for dementia has increased in recent years (Dempsey 2013; 2014). The rationale for this is that ACP enables the person with dementia to remain at the centre of the decision making process in the face of deteriorating cognitive functioning (Mullick et al. 2013). Enhanced patient autonomy has been advocated as a core principle of good quality palliative and end of life care in dementia (van der Steen et al. 2014 (a)). Evidence, however, would suggest that care at this stage is often suboptimal (WHO 2011, 
van der Steen et al. 2014 (a), World Alzheimer's Report 2013). To date, the implementation of ACP in nursing home settings is inconsistent (Dening et al. 2011), resulting in global disparity in practice (Meeusen et al. 2011, van der Steen et al. 2014 (b), Vandervoort et al. 2014).

\section{Background}

Despite evidence that many older people are open to engaging in ACP (Goodwin \& Waters 2009), international research indicates that few people with dementia are provided with the opportunity to engage (Froggatt et al. 2009, Ampe et al. 2015). Furthermore, whilst there is an increased emphasis from policy to embed ACP into practice (van der Steen et al. 2014a), research studies undertaken in the USA (Cavalieri et al. 2002) and Europe (Rurup et al. 2006, Vandervoort et al. 2014), indicate that health professionals, including nurses, are reluctant to engage in the process of ACP with people with dementia. Some possible reasons for this include: ethical concerns when initiating ACP in this context (Thune-Boyle et al. 2010, Stewart et al. 2011); ambiguity regarding their role (Robinson et al. 2013); lack of leadership (Aberdeen \& Angus 2005, Cornally et al. 2015), inconsistency in defining ACP (Cavalieri et al. 2002, Rurup et al. 2006), and questions about the overall culture within an organisation (Ampe et al. 2015 ).

Such concerns highlight the important leadership role for the nursing home manager within this setting (Aberdeen \& Angus 2005, Fleming \& Kayser-Jones 2008). Despite an increase in research in this area, there is a dearth of literature that examines the perspective of this key group of practitioners. To date, only five studies have focused on nursing home managers' perspectives of ACP. It is noteworthy that all of these were undertaken within Europe (Froggatt et al. 2009, Thune-Boyle et al. 2010, Stewart et al. 2011. Ampe et al. 2015, Cornally et al. 2015), with only two focusing specifically in ACP in dementia (Thune-Boyle et al. 2010, Ampe et al. 2015). The studies highlighted challenges when seeking to implement ACP within a nursing home context. These included: difficulties in meeting the expressed wishes within complex and often fragmented health care systems (Robinson et al. 2013); 
challenges of ascertaining the optimal time to initiate ACP (Ampe et al. 2015); health professionals' difficulty in identifying the end of life phase for people with dementia (ThuneBoyle et al. 2010); the important and increasing role of the family (Frogatt et al. 2009; Ampe et al. 2015), alongside other environmental and organisational barriers. Therefore, there is a gap in knowledge focusing on nursing home managers' attitudes, beliefs, knowledge and practice in relation to ACP for people with dementia. Given their central role, it is imperative to ascertain their knowledge and perception of barriers to implementation in practice, in order to identify and inform future potential strategies to address these.

In recognition of the influence of health behaviour models on health professionals' intention to engage in a behaviour, and recent acknowledgement that ACP may be defined as such (Fried et al. 2009), it can be argued that the Theory of Planned Behaviour (Ajzen 2006) provides a useful framework for examining nursing home managers' perspectives. This is supported by previous empirical studies examining ACP across various clinical settings (Zhou et al. 2010, Bullock et al. 2014, Crowe et al. 2015).

\section{Aim}

To examine nursing home managers' knowledge, attitudes, beliefs and current practice towards advanced care planning for people with dementia in long term care settings informed by the Theory of Planned Behaviour.

\section{Research Design}

A cross sectional postal survey was undertaken with nursing home managers in one region of the United Kingdom, as part of a larger scale sequential explanatory mixed methods study. Data were collected over a 3 month period between January -March 2015. This paper reports on the first quantitative phase of the study. 


\section{Setting and participants}

A total population sample of nursing home managers $(n=178)$ who met the inclusion criteria for the study were contacted to participate in a postal survey. Inclusion criteria included: (1) employed in a nursing home registered and regulated by the Regulation and Quality Improvement Authority (the regulatory body for all organisations providing health care in Northern Ireland) and responsible for providing care to people with dementia; (2) registered as a nurse on the Nursing and Midwifery Council Register (UK) and (3) recorded as the registered manager by the regulatory body. Exclusion criteria included: homes which were categorised as providing residential care only; as providing Learning Disability only and homes managed by external / agency staff.

\section{Data collection}

An information pack containing a letter of invitation, information sheet and an anonymous self-administered questionnaire, was posted to all nursing home managers. The participant information sheet included details on the aim of the study and instructions on how to complete the questionnaire. In addition contact details of the research team were included to provide clarification should the need arise. To enhance response rates (Dillman 2006) collaboration was sought with several strategic nursing organisations prior to mailing of the survey (The Royal College of Nursing \& The Independent Health Care Provider) to publicise and encourage participation among nurse manager members. In addition with three reminder letters were issued (Dillman 2006).

\section{Instrument}

As no quantitative tool examining nursing home managers' perspectives of ACP for people with dementia existed, a specific tool was developed for this clinical setting. This was informed by a previously validated instrument examining ACP with specialist oncology nurses (Zhou et al. 2010). Due to acknowledgement that ACP can considered as a health behaviour, (Fried et. 2009) the construction of the tool was informed by the Theory of 
Planned Behaviour (Ajzen 2006). This theory proposes that peoples' intention to engage in behaviour is a key determinant in whether that behaviour occurs. Intention is influenced by three interrelated constructs; Behavioural / Attitudinal Beliefs; Normative Beliefs \& Perceived Behavioural Control (Ajzen 2006).Previous empirical studies examining ACP have found this to be a beneficial framework in which to enhance understanding (Zhou et al. 2010; Bullock et al. 2014; Crowe et al. 2015).

The tool was adapted to reflect the unique contextual landscape of this setting. The rationale for this was that ACP has become increasingly important within this complex environment owing to the increasing numbers of frail older persons with multiple co-morbidities who may be less able to communicate their health care preferences (Badger et al. 2007), and the growing role of family involvement in decision making (Chan \& Pang 2010). Other strategies informing the instrument included a narrative review of the literature (Beck et al. 2015). This provided a synthesis of the main challenges of engaging in ACP with people with dementia in the nursing home setting; which included the increasing role of the family; moral and ethical concerns underpinned by presumptions regarding capacity of the person with dementia to engage; a need for increased training and education as a result of a deficit in knowledge; and a lack of awareness that dementia is a condition that may benefit from a palliative approach to care. These key themes were thus used to aid contextualisation of the adapted instrument to reflect these unique challenges. In addition consultation with international experts $(n=7)$ in the fields of gerontology, palliative care and /or dementia was sought in order to ensure content validity.

The instrument consisted of 48 separate items, separated into 4 sections. The first 22 items on the instrument were variables relating to the TPB (Ajzen 2006), conceptually group together under the three components of the theory; attitude towards the behaviour (11 statements), normative beliefs (5 statements) and perceived behavioural control (6 statements). The remaining items examined understanding and knowledge of ACP (7 statements), current practice (6 statements) and demographics of participants (10 items). 
The section relating to current practice aimed to capture the current levels of engagement of registered managers in relation to $\mathrm{ACP}$. Three open ended questions were included to capture the barriers and facilitators to ACP in this context. Attitudinal and practice items were measured on a five-point Likert scale ranging from 1 (strongly agree) to 5 (strongly disagree). Knowledge and understanding items comprised statements which allowed participants to choose between 'true, false and don't know'. (See Supplementary File Figure 1). The responses within the open ended questions produced qualitative statements, which are included throughout the manuscript and provide unique insight into individual perspectives.

\section{Ethical considerations}

Ethical approval was obtained from NHS Research Ethics Authority (14/NI/0063). All participants were assigned a unique identifier number and consent was presumed upon return of survey instrument.

\section{Data Analysis}

The survey data was analysed using SPSS (version 22). The data did not meet the statistical assumptions for parametric or regression analysis to be undertaken, therefore non parametric tests were employed (Tabachnick \& Fidell 2013, Pallant 2014). Spearman's rank correlation co-efficient was used to investigate the relationships between the five constructs of the instrument; and Mann-Whitney $U$ and Kruskal-Wallis Tests were used to explore the influence of demographic details collected (Pallant 2014). Significance levels were established at $p<0.05$. (Pallant 2014).To prevent response bias several of the items / statements within the tool were worded negatively (Pallant 2014). Content analysis was used to describe the responses to the descriptive open ended questions 


\section{Validity and reliability}

The questionnaire was pre-tested with $10 \%$ of participants $(n=20)$ (Hertzog 2008) of a total sample ( $n=198$ ) who were subsequently excluded from the study. Feedback received from the expert panel previously referred to resulted in minor structural changes to the instrument. This included moving the first section on the draft instrument relating to knowledge and understanding to become the second section, as it was advised that having this placed first may discourage participation and limit response rates. The reliability was measured using Cronbach's alpha, all scales demonstrated acceptable to excellent reliability $(\alpha=0.807)$. Exploratory factor analysis using principal component analysis was used to analyse the psychometric properties and identified six primary components (factors) embedded within the survey, in keeping with the constructs of the instrument. Table one presents the cumulative variance levels achieved, with rotated component matrix and structure matrix scores presented.

\begin{tabular}{|c|c|c|c|}
\hline $\begin{array}{c}\text { Attitudes and } \\
\text { Beliefs Scale } \\
\text { Communality Range } \\
.472-.838\end{array}$ & $\begin{array}{c}\text { Variance explained (\%) } \\
\text { Cumulative Variance (\%) } \\
49.754\end{array}$ & $\begin{array}{c}\text { Rotated Component } \\
\text { Matrix Range }\end{array}$ & $\begin{array}{c}\text { Structure Matrix } \\
\text { Range }\end{array}$ \\
\hline Component 1 & 19.980 & & \\
\hline Component 2 & 12.710 & $.809-.503$ & $.809-.542$ \\
\hline Component 3 & 8.779 & $.740-.539$ & $.762-.563$ \\
\hline Component 4 & 8.277 & $.792-.674$ & $.770-.682$ \\
\hline $\begin{array}{c}\text { Current Practice } \\
\text { Scale }\end{array}$ & Cumulative Variance (\%) & $.760-.407$ & $.755-.425$ \\
Communality Range & 71.008 & & \\
\hline 658 -.753 & 51.153 & $.835-.804$ & $.842-.807$ \\
\hline Component 5 & 19.855 & $.867-.804$ & $.862-.834$ \\
\hline Component 6 & & & \\
\hline
\end{tabular}

Table 1 Principal Component Analysis 


\section{Findings}

From 178 targeted, 116 (66\%) participants' responded. Responses indicate an experienced workforce with most having received training in dementia and palliative care. Respondent demographic characteristics are presented in table 2.

\section{Table 2: Characteristics of Respondents ( $n=116)$}

\section{Characteristic Summary}

\section{Gender}

Female N (\%)

Male N (N\%)

$103(89)$

$13(11)$

Age

$25-44 \mathrm{~N}(\%)$

$45(39)$

$45-65 \mathrm{~N}(\%)$

$71(61)$

Religious Beliefs

Yes N (\%)

$86(74)$

No $\mathrm{N}(\%)$

$26(22)$

Mean years since qualification (SD)

$24(11)$

Mean years as registered manager (SD)

$8.2(7)$

Training

No. who have received dementia training $\mathrm{N}(\%)$

No. who have received palliative care training $\mathrm{N}$

(\%)

No. who have received $\mathrm{ACP}$ training $\mathrm{N}(\%)$

Type of care home registered for *:

Old Age not falling into any other category N (\%)

Over 65 but no not fall into category of old age $\mathrm{N}$

(\%)

Specialised Dementia N (\%)

Terminally III N (\%)

Categorisation of Home

Larger Group Home N (\%)

Independent Group Home N (\%)

Independent Home N (\%)

*please note nursing homes may be registered to care for more than 1 category of care

Total scores

The total scores for each section of the tool were calculated, yielding the creation of five new variables. Due to construction of the likert scale which made up the instrument, lower scores indicated a more positive attitude and higher degrees of perceived behaviour control and engagement. Conversely higher scores of the knowledge total variable indicated a greater degree of knowledge. A summary of the total scores for each section of the instrument are presented in table 3. As evidence by the table there was widespread variation in terms of 
attitudinal beliefs; degree of subjective norm; degree of perceived control, practice and knowledge.

The findings of the survey are presented under four key themes, Knowledge of advance care planning; Attitudes towards advance care planning; Perceived lack of leadership in advance care planning and the Challenge of initiating advance care planning discussions.

\begin{tabular}{|c|c|c|c|c|c|}
\hline & $\mathbf{N}$ & $\begin{array}{l}\text { Minimum } \\
\text { Score }\end{array}$ & $\begin{array}{l}\text { Maximum } \\
\text { Score }\end{array}$ & Mean & Std. Deviation \\
\hline Total Belief Score & 113 & 13.00 & 34.00 & 22.283 & 4.124 \\
\hline \multicolumn{6}{|l|}{$\begin{array}{l}\text { (Score Range 11- } \\
55)\end{array}$} \\
\hline Valid N & 113 & & & & \\
\hline $\begin{array}{c}\text { Total Normative } \\
\text { Score }\end{array}$ & 115 & 5.00 & 19.00 & 12.617 & 2.356 \\
\hline \multicolumn{6}{|l|}{$\begin{array}{c}\text { (Score Range 5- } \\
25)\end{array}$} \\
\hline Valid N & 115 & & & & \\
\hline $\begin{array}{l}\text { Total Perceived } \\
\text { Control Score }\end{array}$ & 116 & 6.00 & 26.00 & 13.302 & 4.286 \\
\hline \multicolumn{6}{|l|}{$\begin{array}{l}\text { (Score Range 6- } \\
30)\end{array}$} \\
\hline Valid N & 116 & & & & \\
\hline $\begin{array}{l}\text { Total Practice } \\
\text { Score (Score } \\
\text { Range 6-30) }\end{array}$ & 114 & 6.00 & 29.00 & 16.474 & 4.360 \\
\hline Valid N & 114 & & & & \\
\hline $\begin{array}{c}\text { Total Knowledge } \\
\text { Score (Score } \\
\text { Range 0-7) }\end{array}$ & 116 & 0 & 6.00 & 3.293 & 1.306 \\
\hline
\end{tabular}

Table 3 Total Scores for Instrument Domains

Knowledge and attitudes regarding advance care planning for people with dementia

The results demonstrated that nursing home managers' knowledge of ACP was poor (see table 4$)$, with less than half the sample $(47 \% n=54)$ being able to respond correctly to more 
than 3 of the 7 knowledge questions (see table 3). There was great variation in knowledge. For example, whilst over half the sample reported they had the necessary knowledge to conduct ACP conversations with residents with dementia $(51 \% n=59)$ and their families $(61 \% n=72)$, key differences were reported in relation to legal aspects, which highlighted an overall lack of awareness $(90 \% n=104)$ of the legislation governing the ACP process (statement 3). Moreover, ACP was viewed as a legally binding document $(41 \% n=48)$; related only to medical interventions $(50 \% n=58)$ with little recognition of the voluntary nature of the process (statements 3-5). Although a significant proportion of respondents believed the person with dementia must be involved in the ACP discussion $(67 \% n=78)$, only $19 \%$ $(n=22)$ of them considered that they actually wanted to be involved (statement 19). This lack of knowledge was also evident within some of the more open qualitative responses, with lack of knowledge being identified as a key barrier towards ACP in this setting. Several respondents identified an overall "lack of knowledge of staff" (RM 15), whilst others reported a "lack of personal knowledge of ACP" (RM24). It was noteworthy that whilst those who had attended specific ACP training $(24 \% \mathrm{n}=28)$ did not have improved knowledge as a result $(\mathrm{u}=991, \mathrm{z}=-1.28, \mathrm{p}=0.20, \mathrm{r}=.-.12)$, they were likely to have a more positive attitude towards ACP $(u=799, z=-2.24, p=0.03, r=-.20)$. Interestingly it was noted that those managers who had received dementia training $(82 \% n=95)$ were more likely to have enhanced knowledge of ACP $(u=560, z=-2.39, p=0.02, r=.23)$. There was a small negative correlation between attitudinal and knowledge scores, indicating those respondents with increased knowledge of ACP had a more positive attitude towards ACP in this context. (Rho $=-.25, n=113, p=0.01$ )

Overall, it was found that there was a cautious attitude towards ACP (see table 4). The majority of respondents recognised the importance of ACP for residents with dementia and the theoretical benefits, such as a reduction in decisional crisis occurring and an enhancement of satisfaction for residents and family (statements 10-12,17, 20). However, it was also noted that $48 \%(n=56)$ of respondents considered that ACP would actually increase futile treatment at the end of life (statement 15). A considerable proportion of 
respondents also perceived that ACP may also impact negatively on a resident's sense of hope $(34 \% n=39)$. Implementation was influenced by two key factors; the stage of dementia (statements $13 \& 14$ ) and an assumption that people with dementia would not want to be involved in this process (statements $18 \& 19$ ). It was found that the majority of respondents identified the nursing home setting as too late to begin ACP, "People with advanced dementia are unable to make choices" (RM39).

"ACP needs to be discussed with dementia patients prior to admission to nursing home" (RM16).

In addition, there was an assumption that people with dementia $(81 \% n=94)$ do not want to know about future care options (statement 19). This contradicts with the views expressed that families want to be informed of treatment options $(91 \% \mathrm{n}=106)$ (statement 21$)$. Spearman correlations revealed that those with more positive attitudes were likely to have a greater degree of perceived behavioural control ( $r h o=0.29, n=113, p<0.0$ ) and to therefore engage in the ACP process (rho=0.21, $n=113, p=0.03$ ). 
Reported Knowledge Statements

1. I have sufficient knowledge about how to conduct ACP conversations with families.

2. I have sufficient knowledge about how to conduct ACP conversations with residents with dementia.

Legalities and Components Statements

3. The Mental Capacity Legislation due to be Implemented in Northern Ireland in 2016 mandates that all individuals with dementia should have an ACP in place.

4. An ACP is a legally binding document.

5. An ACP for people with dementia only relates to specific medical interventions.

6. A resident with dementia may change his /her mind regarding the contents of their ACP.

7. A family member of someone with dementia may change the contents of their family members' ACP.

8. The person with dementia must be involved in the ACP discussion.

9. During an ACP discussion for someone with dementia their family member must be involved.
Participants $(\mathrm{n}=)$ who

Strongly Agreed / Agreed

with statement

$61 \%(n=72)$

$51 \%(n=59)$

Participants who responded correctly to knowledge statements $(n=)$

$$
\begin{aligned}
& 10 \%(n=12) \\
& 41 \%(n=48) \\
& 50 \%(n=58) \\
& 84 \%(n=97) \\
& 46 \%(n=53) \\
& 67 \%(n=78) \\
& 31 \%(n=36)
\end{aligned}
$$

\section{Statements}

\section{Attitudes towards ACP}

10. ACP will not speed up the dying process in residents with dementia.

11. ACP discussions are very important for residents with dementia.

12. ACP can reduce EOLC decisional crisis in residents with dementia

13. ACP should be discussed regardless of stage of dementia.

14. The best time to discuss ACP is when residents are not seriously ill.*

15. ACP decreases the likelihood of futile treatment at EOL.*

16. ACP discussions will not destroy a resident with dementia sense of hope.*

17. ACP can improve residents' satisfaction with their care.

17. Most residents with dementia want to know about their diagnosis, prognosis and treatment/ care options.

18. Most residents with dementia, if asked, want to discuss their wishes for future health care wishes. *

19. ACP can improve families' satisfaction with care.

20. Most families want to know about their diagnosis, prognosis and available care options.

$$
\begin{gathered}
80 \%(n=92) \\
90 \%(n=104) \\
91 \%(n=106) \\
61 \%(n=68) \\
92 \%(n=107) \\
52 \%(n=60) \\
66 \%(n=77) \\
70 \%(n=81) \\
43 \%(n=50) \\
19 \%(n=22) \\
91 \%(n=105) \\
91 \%(n=106)
\end{gathered}
$$

\section{Table 4 Understanding, Knowledge and Attitudes * Items worded negatively in original instrument and reversed for analysis purposes}

Perceived lack of leadership for advance care planning and the importance of peer support (Table 5)

Nursing home managers reported that implementation of ACP was influenced by two important underlying conditions. Firstly a lack of leadership, with less than half of nursing home managers perceiving it to be their role $(47 \% n=54)$. This is further compounded by the fact that few viewed it as the GPs' (statement 3) or the registered nurses' responsibility (statement 4). 
Secondly, with confusion regarding legalities, $78 \%(n=90)$, respondents highlighted the important influence of colleagues on the process of implementing ACP in this setting. Spearman correlation results indicated a moderate correlation (Rho=:0.42, $n=115, p<0.0$.) between the level of peer support and subsequent perceived control in terms of ability to engage in ACP, with this resulting in increased likelihood to engage ( $R h o=0.47, n=113$, $p<0.0$ ). Moreover, a moderate positive relationship was also evident between the degree of perceived behavioural control present and the resulting effect on ACP practice $(R h o=0.43$, $n=115 p<0.0)$.

The Challenge of Initiating advance care planning conversations (Table 5)

Various challenges in initiating ACP were identified. Firstly, the terminology used to describe ACP discussions was deemed to be an influencing factor on implementation. For example, when statements were framed within a 'palliative care' or 'future care wishes' language, the respondents expressed higher degrees of comfort and engagement (statements 5,6,9,12). However, when the term 'advance care planning' was used (statements 7,8,10,11,13,14), only 2 respondents reporting that all residents with dementia or their families had ACP discussions in their organisations. The importance of terminology was also evident within the qualitative responses, with several responses indicating the need for greater clarification of the terms and the use of "universal language for ACP" (RM28)._Secondly, there was recognition of the sensitive nature of ACP discussions. Respondents highlighted the difficulty for nurses in discussing death, with one participant stating "death is a tough subject" (RM59), whilst another referred to "the difficulty of planting the first seed" (RM63). This resulted in the identified need for staff training in how to deal sensitive conversations as a potential facilitator for the process of ACP in this setting.

Correlation with demographics reported no significant difference on the level of perceived control in engaging in ACP, with the exception of those who either indicated they had religious or spiritual beliefs $(m d=13, n=86)$ or with those who indicated they did not have religious/spiritual beliefs $(m d=12, n=26)$. The results indicated that those with 
religious/spiritual beliefs reported less perceived control in relation to ACP conversations with both families and people with dementia ( $u=808.50, z=-2.12, p=0.03, r=0.20)$. A Kruskal- Wallis test revealed a statistically significant difference in practice and engagement across the three different types of nursing homes represented (Large Group Homes, $n=53$; Independent Group Homes, $n=26$, Independent Homes, $n=37), X^{2}(2, n=116)=6.12, p=$ 0.05). Those in independent homes recorded a lower median score of 14 for current practice and engagement, compared to a median score of 16 for both those in large group homes and independent group homes. This indicated those working in independent homes were more likely to engage in ACP.

\section{Peer Support}

Statements

1. My colleagues support me in discussing ACP with residents and their families.

\section{Ownership of the ACP process}

2. It is my responsibility as RM to discuss ACP with residents with dementia and their families.

3. ACP discussions for people with dementia are the GPs responsibility.

4. ACP discussions for people with dementia are the registered nurses responsibility.

\section{Challenges of initiating ACP}

5. I feel comfortable discussing issues relating to future health care wishes with family members.

6. I feel comfortable discussing issues relating to future health care wishes with residents with dementia.

7. I feel comfortable discussing ACP with families of people with dementia.

8. I feel comfortable discussing ACP with residents with dementia.
Participants $(\mathrm{n}=)$ who Strongly Agreed / Agreed with statement

$78 \%(n=90)$

$48 \%(n=56)$

$37 \%(n=49)$

$90 \%(n=104)$

$82 \%(n=95)$

$85 \%(n=99)$

$57 \%(n=66)$

9. In my current practice, I routinely talk with

$58 \%(n=67)$ residents with dementia about palliative care options when appropriate.

10. In my current practice I routinely initiate ACP discussions with residents with dementia.

11. In my current practice I routinely follow up ACP discussions with residents with dementia.

12. In my current practice I routinely talk with residents' families about palliative care options when appropriate.

13. In my current practice I routinely initiate ACP discussions with families.

14. In my current practice I routinely follow up ACP discussions with families.

$29 \%(n=33)$

$34 \%(n=39)$

$84 \%(n=97)$

$55 \%(n=63)$

$61 \%(n=70)$

Table 5 Peer support, ownership and challenges of initiating ACP 


\section{Barriers and Facilitators to ACP within the nursing home setting}

Two open ended questions exploring perceived barriers and facilitators in engaging with ACP were included in the survey. It was found that challenges were encountered, such as time constraints, lack of practical guidance, family conflict and the desire to protect the person with dementia. Despite these, respondents also reported potential ways and strategies in which these challenges could be overcome (see table 6).

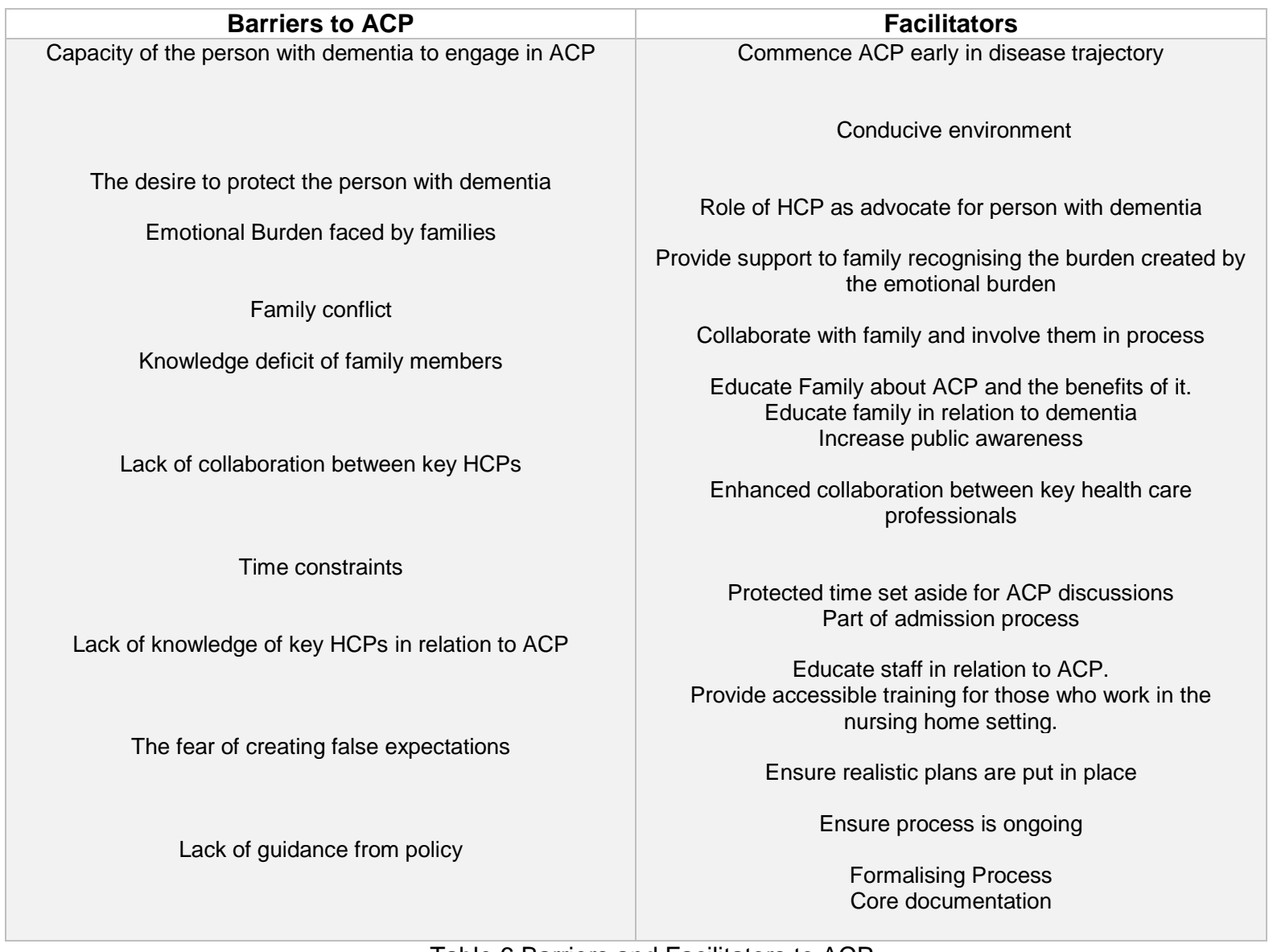

Table 6 Barriers and Facilitators to ACP

\section{Discussion}

The findings of this study clearly indicate that nursing home managers have a lack of knowledge and have reserve towards ACP for people with dementia. This is compounded by the complexity of the environment in which they work, and an overall lack of leadership and ownership with regards to ACP for people with dementia in this setting. The components of 
the theory of planned behaviour and the overall aims of the study provide a useful framework to outline the subsequent discussion of the findings.

\section{Knowledge of Advance Care Planning}

Nursing home managers struggled with implementation in practice due to a lack of knowledge. Similar findings have been noted in previous studies which proposed the need to improve the knowledge of those engaging in, and implementing ACP in this setting. There is a particular need for increased knowledge regarding the legal and ethical aspects (Robinson et al. 2012. Vandevoort et al. 2014. Romoren et al. 2016).

Therefore important questions exist concerning the education and training process for ACP (Detering et al. 2014). This study highlighted that current ACP training is inadequate, with it failing to address the knowledge deficit. In light of the findings that those with increased knowledge had more positive attitudes towards ACP, the onus to address the current deficit in knowledge is greatly increased. Previous interventions involving training programmes showed significant improvement in not only attitude towards ACP, but also positively impacted upon engagement (Detering et al. 2014). Therefore future interventions need to be preceded by tailored training programmes which address the specific practical, moral and ethical concerns of nursing home managers.

\section{Attitudes towards ACP}

As leaders in this setting, on the whole respondents viewed ACP cautiously, questioning its' applicability and effectiveness. This may be impeding implementation in this setting. Previous empirical studies have questioned the evidence base for ACP (Dening et al. 2011. Robinson et al. 2013), with a recent call for future research to identify which elements of ACP are most beneficial through methodologically sound studies (Rietjens et al. 2016). This would assist nursing home managers in seeing the potential applicability of specific elements for this context, and particularly for people with dementia. Robinson et al. (2012) in their systematic review of the evidence of ACP in dementia concluded that there was limited 
evidence of the effectiveness of ACP for people with dementia. This finding is supported by previous systematic reviews in this area (Dening et al. 2011. Sharp et al. 2013). This is in contrast however the conclusions reached by with van der Steen et al. (2014b) in their systematic review, who concluded that despite the limited evidence base, ACP has the potential to benefit people with dementia in relation to end-of-life decision making. Despite respondents concerns regarding the effectiveness and outcomes of ACP, they did acknowledge the theoretical value, such as reduction in decisional crisis. Therefore, it is important that the evidence base for the use of ACP for people with dementia in this setting is clearly outlined and communicated to nursing home managers in order to impact on both their level of knowledge and overall attitudes.

It was also noted that the attitudes of the respondents were influenced by several factors. Firstly, questions as to whether the person with dementia had the capacity to be able to engage with ACP in this setting. Due to late stage at which people with dementia are now entering the long term care setting, concerns regarding the capacity of the person with dementia to participate in ACP have led to a gap between policy and practice (Ampe et al. 2015). At the core of the traditional ethos of ACP, is the involvement of the patient in the discussion (Mullick et al. 2013). Yet the findings of this study suggested that within this clinical setting this is often not realised. A similar finding has been noted in other European studies (Rurup et al. 2006, Vandervoort et al.2014). Therefore it is vital that discussions need to commence early in the disease trajectory, in order to ensure the person with dementia remains central to the process, as opposed to outside it (Poppe et al. 2013). In light of the potential of ACP to allow individuals to express preferences for all aspects of care they would like to receive, in anticipation of an inability to make such wishes known, autonomy should be encouraged throughout the disease trajectory, recognising that people with dementia often retain ability to express their wishes in relation to 'in the moment care'.

Secondly, the findings demonstrated that they perceived that the person with dementia does not want to, or is not able to participate in ACP discussions. This is in stark contrast with 
previous research which suggested people with dementia are willing and want to be involved (Goodwin \& Waters 2009, Poppe et al. 2013). It must be noted that people with dementia are capable and should be included in the decision making process in relation to their healthcare and wider needs, with autonomy promoted by those caring for them. However, this study evidenced this is often restricted due to the rather narrow understanding of the ACP process, relating only to end-of-life decisions and subsequent presumptions regarding capacity of the person with dementia.to engage. Without formal standardised guidance, professionals often turn to the next of kin for guidance on when and how to implement ACP. Similar findings were noted in a Norwegian study undertaken with physicians, which concluded staff place greater emphasis on the views of the family, to the exclusion and detriment of the person with dementia (Romoren et al. 2016).

Thirdly, the findings demonstrated the potential influence of terminology when initiating discussions relating to future health care. The respondents expressed a reluctance to use ACP terminology to structure the discussion. Rather it was found that they preferred to frame ACP discussions within a palliative or future care wishes context. This may be as a result of the knowledge deficit outlined above, and underpinned by the lack of clarity within the literature in terms of providing a clear and consistent definition (Cavalieri et al. 2002, Rurup et al. 2006, Vandervoort et al. 2014). However the recommendations of a wide range of policy initiatives propose that ACP should be seen as an integral component of good quality palliative dementia care (WHO 2011), with quality indicators for palliative care in dementia reflective of such (De Roo et al. 2013, Candy et al. 2015).

\section{Current Practice}

This study highlighted that the current practice behaviours of nursing home managers are underpinned by several elements, reflective of the key constructs of the Theory of Planned Behaviour (Ajzen 2006). These included the impact of peer support from colleagues, influencing not only in terms of the degree of control respondents reported, but also actual behaviour. Current recommendations to improve care within the dementia context 
highlighted the need for nursing home managers to be "active role models" (Rokstad et al. 2015 p23). However, the findings from this study question their ability to do so due to a lack of role identification, ownership and leadership.

One possible explanation for the lack of ownership may stem from the blurred demarcation of carrying the burden of leadership, whilst remaining and being accountable as a nurse (Fleming \& Kayser-Jones 2008). The reality of balancing administrative and managerial tasks may lead to the detriment of spending time eliciting the needs of residents. However, despite the lack of opportunities for them to 'actively engage', they do have a pivotal role to play in facilitation of the process at an organisational level. Therefore, there is a need for strong nursing leadership within this setting (Aberdeen \& Angus, Fleming \& Kayser-Jones 2008). However, the findings of this study indicate there is a current lack of knowledge, skills and support to become the ideal clinical leaders required to influence practice in this area.

Finally, practice is influenced by a reluctance to facilitate ACP discussions. This study found knowledge reflected more clinical and end-of-life understanding of $\mathrm{ACP}$, resulting in subsequent discomfort in facilitating the overall process. It can be argued that traditionally nurses struggle with discussions relating to end of life care (Baldwin \& Woodhouse 2011, Davis 2015). Nurses are expected to be advocates for those in their care, yet are often challenged when expected to be involved in discussions relating to end of life care (Davis 2015). Research indicates they are often uncomfortable with this role, seeing their role as one of preservation of life, even if this is at odds with what the person may want (Baldwin \& Woodhouse 2011). However, ACP needs to be viewed, understood and practiced in its wider sphere, with recognition that within this context it should not be restricted to end of life care decisions. One approach that may address this is the promotion of a public health approach to palliative care and more specifically to ACP ( Sallnow et al. 2012). Research indicates that current knowledge and understanding of palliative care within society as a whole is insufficient (Conway 2008, Mcllfatrick et al. 2013), with this also evident in those who work in health care (Paul \& Sallnow 2013). It is proposed that this may be addressed through 
educational initiatives that involve the whole spectrum of society, facilitating the integration of a palliative care approach into the wider community (Stjernswared et al. 2007). This may help to address current misconceptions about palliative care (Mcllfatrick et al. 2013), of which ACP is a key component (Candy et al. 2015). Addressing these aspects may enable nurses, families and people with dementia to be more informed and equipped earlier for discussions regarding future wishes.

\section{Limitations}

The geographical location of the study was limited to one region of the UK, thus caution must be applied when discussing findings in relation to the international setting. The adoption of a quantitative methodology for this phase restricted the ability for further exploration and probing to occur. However this phase will be followed sequentially by an indepth qualitative phase which will examine in detail perspectives expressed within this quantitative phase. There is the potential for response bias, with potential for those who responded to the survey having different perspectives than the general nursing home management population. Lastly, acknowledgement is made to the challenges encountered in relation to self-reporting methodologies.

\section{Conclusion}

In order for ACP to be implemented within this setting it is vital that nursing home managers are supported to carry out their unique and challenging role; enabled to facilitate the implementation of ACP within their organisations, and provided with the necessary resources to help them to improve their knowledge in relation to both dementia and ACP. This will allow for dissemination of such to their nursing staff, and enable them to become active leaders and role models in the process. Future training needs to clarify the true purpose of ACP, with acknowledgement of the wider components, integrated into society through a public health approach. The benefits of the TPB as an underlying structure to the 
study have been reinforced by the findings; and enhanced understanding of the factors that influence engagement in the process.

\section{Relevance to Clinical Practice}

This study has clearly demonstrated that knowledge is poor among this group of practitioners, resulting in misconceptions regarding the true purpose of ACP. As a result negative connotations are present. Therefore there is a need for targeted and improved ACP training to address the knowledge deficit, which focuses on the wider aspects of ACP, including the practicalities of facilitation of the process in this setting. In addition policy needs to establish clear guidance in relation to role clarification, in order to address the current lack of identification evident among nurses in relation to the process of ACP. The embedding of relational autonomy into many nursing codes of conduct puts the onus for those in senior nursing roles to ensure ACP is offered and delivered under their leadership in this setting. Whilst they may not see it as their role to 'actively engage' at a personal level, they need to ensure facilitation of the process is delivered under their direction.

\section{Acknowledgements}

The authors would like to acknowledge the contribution of the following people towards the development of the survey instrument: Prof G Zhou \& Prof B A Swan for granting access to their validated instrument. Prof K Froggatt for her contribution in reviewing the instrument. To the Royal College of Nursing ( $\mathrm{RCN})$ Northern Ireland and the Independent Health Care Providers Organisation (IHCP) for their assistance in recruitment of participants. To the registered nursing home managers who kindly took the time to complete the survey instrument.

\section{Funding Declaration}

The first author (EB) received financial support from the Department of Education and Learning.

\section{Declaration of conflict of interest}


The Authors declare that there is no conflict of interest.

\section{References}

Aberdeen.S \& Angus.J (2005) A Systematic Approach to Curricula Development for Aged Care Leadership Educational Gerontology 31 pp481-497 ISSN: 0360-1277 print / 1521-0472 online DOI: 10.1080/03601270590928198

Ajzen, I. (2006). From intentions to actions: A theory of planned behavior. In J. Kuhi \& J. Beckmann (Eds.), Actionócontrol: From cognition to behavior (pp. 11-39). Springer Publising. ISBN:978-3-642-69746-3

Ampe,S. Sevenants,A. Smets,T. Declercq,A. \& Van Audenhove. (2015) Advance care planning for nursing home residents with dementia: policy vs. practice. Journal of Advanced Nursing. 00(0), 000-000. Doi: 10.1111/jan.12854Assisted Decision-Making (Capacity) Bill (2013) Explanatory Memorandum [Internet]. Oireachtas. Available from http//www.oireachtas.ie/documents/bills28/bills/2013/8313/b8313d

Badger.B ,Thomas. K \& Clifford.C (2007). Raising standards for elderly people dying in care homes. European Journal of Palliative Care, vol. 14, no. 6, pp. 238-241.

Baldwin,M.A.\& Woodhouse.J (2011) Key Concepts in Palliative Care. Sage Publications.

Beck,E.R. Mcllfatrick,S.J., Hasson.F \& Leavey.G (2015) Health care professionals perspectives of advance care planning for people with dementia living in long-term care settings: A narrative review of the literature. Dementia. DOI: $10.1177 / 1471301215604997$

Brinkman-Stoppalenburg,A., Rietjens,A,C,J,. \& van der Hiede,A. (2014) The effects of advance care planning on end of life care: A systematic review. Palliative Medicine Vol 28 (28). 1000-1025. DOI: 10.1177/0269216314526272.

Bullock,K. Hall,J.K.\& Leach,M.T. (2014) End of Life Care Among Older Minorities. In Handbook of Minority Aging Edited by Whitfield,K.E \& Baker.T Chapter 16 265-277 Springer Publishing Company New York

Candy,B. Elliott,M,, Moore,K. Vickerstaff,V., Sampson,E,L \& Jones,L. (2015) UK quality statements on end of life care in dementia: a systematic review of research evidence $B M C$ Palliative Care 14 (51) Doi: 10.1186/s12904-015-0047-6

Cavalieri, T.A., Latif, W., Ciesielski, J., Ciervo Jr., C.A. \& Forman, L.J. 2002. How physicians approach advance care planning in patients with mild to moderate Alzheimer's disease. Journal of the American Osteopathic Association, 102 (10) 541-544

Chan.H,Y. and Pang,S.M (2010) Let me talk-An advance care planning programme for frail nursing home residents. Journal of Clinical Nursing, vol. 19, no. 21-22, pp. 3073-3084,

Cornally.N,m McGlade,C. Weathers,E. Daly,E. Fitzgerald,C. O'Caoimh, Coffey \& Molloy,W.D. (2015) Evaluating the systematic implementation of the 'Let Me Decide' 
advance care planning programme in long term care through focus groups; staff perspectives. BMC Palliative Care 14 (55) Doi: 10.1186/s12904-015-0051-x

Crowe.L, Quinn,L,. Chenoweth,L. Kularatna.S. Boddy,J. \& Wheeler,A.J (2015) Advance Care Planning for Older Australians Living in the Community - The Impact of Group Education Session. Sage Open June 2015 5(2) Doi: 10.1177/2158244015593117

Davis. R (2015) Starting end-of-life conversations. Nursing Times 111 (4) 18-21

De Roo,M. Leemans,K. Claessen,J.J.S., Cohen,J. Pasman,W. Deliens,L \& Francke,A,L. (2013) Quality Indicators for Palliative Care: Update of Systematic Review. Journal of Pain and Symptom Management Vol 46 (4) 556-572 DOI: 10.1016/i.jpainsymman.2012.09.013

Dempsey, D. 2013. Advance care planning for people with dementia: benefits and challenges. International journal of palliative nursing, 19 (5) 227-234 DOI: 10.12968/ijpn.2013.19.15.227

Dempsey.D. (2014) Advance care planning: taking time now will save time later. National Research Council. 16 (5) 269-272 10.12968/nrec.2014.16.5.269

Dening,K.H, Jones,L. \& Sampson,E.L. (2011) Advance care planning for people with dementia: a review. International Psychogeriatrics. 23 (10) 1535-1555 DOI:1017/S104161021001608

Detering.K. Silvester.W. Corke.C. Milnes.S, Fullam,R. Lewis.V. \& Renton.J. (2014) Teaching general practitioners and doctors-in-training to discuss advance care planning: evaluation of a brief multimodality education programme. BMJ Supportive and Palliative Care. DOI: 10.1136/bmjspacare-2013-000450

Dillman, D.A. (2006). Mail and Internet Surveys: The Tailored Design Method (2nd ed.). New Jersey: John Wiley \& Sons. ISBN 978-0-470-03856-7.

Fleming,M.J \& Kayser-Jones (2008) Assuming the Mantle of Leadership - Issues and Challenges for Directors of Nursing Journal of Gerontological Nursing 34 (11) 18-25 10.3298/00989134-20081101-05

Fried,T.R., Bullock.K., lannone.L. \& O'Leary,J.R. 2009. Understanding advance care planning as a process of health behaviour change. Journal of American Geriatric Society. 57. 1547-1555. DOI: 10.1111/j.1532-5415.2009.02396x

Froggatt,K., Vaughan.S., Bernard.C. \& Wild.D (2009) Advance care planning in care homes for older people: an English perspective. Palliative Medicine. 23. 332-338 DOI:10.1177/0269216309103802

Godwin,B. \& Waters,H. (2009) 'In Solitary confinement': Planning end-of-life well-being with people with advanced dementia, their family and professional carers. Mortality 14 (3).265285

Gott M, Gardiner C, Small N, Payne S, Seamark D, Barnes S. (2009) Barriers to advance care planning in chronic obstructive pulmonary disease. Palliative Medicine 23 (7) 624-648 DOI:10.117710269216309106790

Hertogh, C.M.P.M. 2006. Advance care planning and the relevance of a palliative care approach in dementia. Age and Ageing, 35 (6) 553-555. DOI: 10.1093/ageing/afl103 
Hertzog, M.A. (2008). Considerations in determining sample size for pilot studies. Research in Nursing \& Health, 31,180-191. DOI: 10.1002/nur.20247

Mcllfatrick.S. Hasson.F. McLaughlin.D. Johnstin.G. Roulston.L. Noble.H. Kelly.S. Craig.A \& Kernohan.G. (2013) Public awareness and attitudes toward palliative care in Northern Ireland. BMC Palliative Care 12:34 http://www.biomedcentral.com/1472-684X/12/34

Meeusen,K. Van den Block,L. \& Deliens,L. (2011) Advance Care Planning: International Perspectives in Living with Ageing and Dying: Palliative and End of Life care for Older People. Chapter 9. Edited by Gott,M. \& Ingleton,C. Oxford University Press

Mullick.A., Martin.J. \& Sallnow.L. (2013) An introduction to advance care planning in practice. BMJ 10. 347:f6064

Pallant Pallant, J. (2014) SPSS survival manual: a step by step guide to data analysis using SPSS version21. $\left(5^{\text {th }}\right.$ ed). United Kingdom: Open University Press.

Paul.S \& Sallnow,L. (2013) Public Health Approaches to end of life care in the UK: an online survey of palliative care services. BMJ Supportive and Palliative Care 3 pp196-199. DOI:

DOI: 10.1136/bmjspare-2012-000334

Poppe M, Burleigh S, Banerjee S (2013) Qualitative Evaluation of Advanced Care Planning in Early Dementia (ACP-ED) Plos One 8 (4). DOI: 10.1371/journal.pone.0060412

Rietjens.J., Korfage.I. \& van der Heide.A. (2016) Advance care planning: Not a panacea. Palliative Medicine. Vol. 30 (5) 421-422 DOI: 10.1177.0269216316642963

Robinson, L., Dickinson, C., Rousseau, N., Beyer, F., Clark, A., Hughes, J., Howel, D. and Exley, C. (2012) A systematic review of the effectiveness of advance care planning interventions for people with cognitive impairment and dementia. Age \& Ageing 41 pp263269. DOI: $10.1093 /$ ageing/afr148

Robinson, L., Dickinson, C., Rousseau, N., Beyer, F., Clark, A., Hughes, J., Howel, D. and Exley, C (2013) A qualitative study: Professionals' experiences of advance care planning in dementia and palliative care, 'a good idea in theory but....'. Palliative Medicine. 27 (5). 401408. DOI: $10.1177 / 0269216312465651$

Rokstad.A.M.M Vatne.S Engedal.K \& Selbek.G (2015) The role of nursing leadership in the implementation of person-centred care using Dementia Care Mapping: a study in three nursing homes Journal of Nursing Management 23 pp15-26 DOI: 10.1111/jonm.12072

Romøren, M., Pedersen, R. and Førde, R., 2016. How do nursing home doctors involve patients and next of kin in end-of-life decisions? A qualitative study from Norway. BMC medical ethics, 17(1), p.1. DOI: 10.1186/s12910-016-0088-2

Rurup, M.L., Onwuteaka-Philipsen, B.D., Pasman, H.R.W., Ribbe, M.W. and van der Wal, G. 2006. Attitudes of physicians, nurses and relatives towards end-of-life decisions concerning nursing home patients with dementia. Patient education and counseling, 61 (3), 372-380. DOI: 10.1016/j.pec.2005.04.016

Sallnow.L, Jumar.S \& Kellehear.A (2012) International Perspectives on Public Health and Palliative Care. Oxon. Routledge 
Sharp.T., Moran.E., Kuhn.I. \& Barclay.S. (2013) Do the elderly have a voice? Advance care planning discussions with frail and older individuals: a systematic literature review and narrative synthesis. British Journal of General Practice. October. 657-668. DOI: 10.3399/bjgp13X673667

Stewart, F., Goddard, C., Schiff, R. and Hall, S. 2011. Advanced care planning in care homes for older people: A qualitative study of the views of care staff and families. Age and Ageing, 40 (3), 330-335. DOI: 10.1093/ageing/afr006

Stjernsward.J, Foley.K.M \& Ferris.F. (2007) The Public Health Strategy for Palliative Care. Journal of Pain and Symptom Management. 33 (5) pp 486-493. DOI: 10.1016/j.jpainsymman.2007.02.016

Tabachnick.B.G \& Fiddell,L.S. (2013) Using Multivariate Statistics. Pearson Education: Boston.

Thuné-Boyle, I., Sampson, E.L., Jones, L., King, M., Lee, D.R. and Blanchard, M.R. 2010. Challenges to improving end of life care of people with advanced dementia in the UK. Dementia (14713012), 9 (2) 259-284. DOI: 10.1177/1471301209354026

van der Steen,J.T, Radbruch,L., Hertogh,C.M.P, de Boer,M.E, Hughes,J.,Larkin,P., Francke,A.L., Junger,S., Gove.D., Firth,P., Koopmans,R. \& Volicer,L. (2014a). White Paper defining optimal palliative care in older people with dementia: A Delphi study and recommendations from the Association for Palliative Care. Palliative Medicine 28 (3) 197209. DOI: $10.1177 / 0269216313493685$

van der steen,J,T. van Soest-Poortvliet.M.C., Hallie-Heierman.M., OnwuteakaPhilipsen.B.D., Deliens.L., de Boer.M.E., Van den Block.L., van Uden.N., Hertogh.C.M.P. \& de vet.H.C.W. (2014b) Factors Associated with Initiation of Advance Care Planning in Dementia: A systematic Review. Journal of Alzheimer's Disease. (40) 743-757. DOI: 10.3233/JAD-131967

Vandervoort, A., Houttekier, D., Van Den Block, L., Van Der Steen, J.T., Stichele, R.V. and Deliens, L. 2014. Advance care planning and physician orders in nursing home residents with dementia: A nationwide retrospective study among professional caregivers and relatives. Journal of pain and symptom management, 47 (2), 245-256. DOI: 10.1016/jpainsymman.2013.03.009

World Alzheimers Report (2013) Journey of Caring: An analysis of long-term care for dementia. Alzheimer's Disease International Journal. Edited by Prince.M., Prina.M. \& Guerehet.M.

World Health Organisation (WHO). (2011). Palliative care for older people: Better practices. In S. Hall, H. Petkova, A. D. T. M. Costantini \& I. J. Higginson (Eds). ISBN 978928900224 0

Zhou.G, Stoltzfus.J.C, Houldin,A,D., Parkes,S,M. \& Swan.B.A. (2010) Knowledge, attitudes and practice behaviours of oncology advanced practice nurses regarding advance care planning for patients with cancer. School of Nursing Faculty Papers 31 http://jdc.jefferson.edu/nursfp/31. 
